Increasing the versatility of the

Scientific Prototype 3-channel tachistoscope

MICHAEL H. ROWE and JACK $H$. SANDWEISS, CALIFORNIA STATE COLLEGE AT LOS ANGELES, LOS Angeles, California 90032

Because of its relatively low cost and high degree of flexibility, the Scientific Prototype Model GB 3-channel tachistoscope is one of the more popular commercially available units. With this instrument, precise tachistoscopic presentation of one, two, or three visual stimuli can be achieved, and a variety of sequences and temporal relationships can be programmed easily without the aid of any external devices. However, in experiments requiring the successive presentation of three stimuli (i.e., masking studies), it is difficult to program internally interstimulus intervals between any pair of stimuli. Nevertheless, through the use of simple RC networks in conjunction with the front panel functions of the instrument, such intervals can be easily and inexpensively provided.

In normal operation, all connections between each channel timer and the relevant stimulus lamp are internal. There are, however, front panel provisions whereby appropriate logic signals can

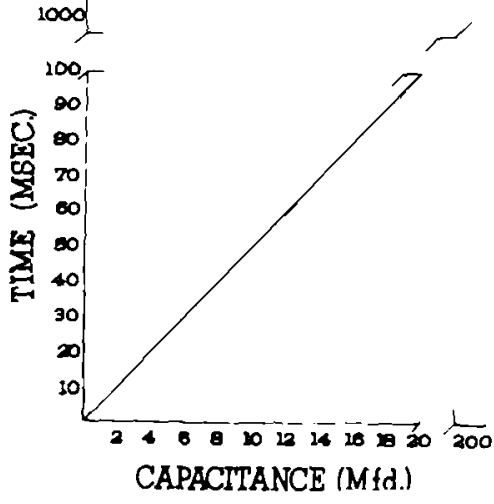

Fig. 1. Time delay as a function of capacitance with a constant 10-ohm resistance.

maintain on or off states of the lamp driver independent of the state of the channel timer. The channel timer itself is operated by applying a $-7 . \mathrm{V}$ de logic signal to the timer input jack and provides an identical $-7 \cdot \mathrm{V}$ dc signal through the gate output jack during its on state. In addition, the inverse output jack provides a $-7-\mathrm{V}$ dc logic signal during the off state of the timer, which can be used to trigger subsequent channels for sequential presentations.

In order to obtain specific interchanne intervals when all three channels are involved in sequential stimulus presentation, the procedure is simply to have any given lamp driver momentarily inhibited by the gate output of its own channel timer through an appropriate RC circuit. This is accomplished by running a lead from the gate output of any channel timer through the $\mathrm{RC}$ circuit into the inhibit jack of its own lamp driver. In this way, the lamp driver is maintained in an off state for a duration determined by the RC time constant even though the channel timer is on.

Such an arrangement has been set up in our laboratory using a constant 10-ohm resistance in series with capacitance values ranging from 1 to $200 \mathrm{MF}$. All time constants were measured by using a Tektronix Model 502A dual-beam oscilloscope to monitor the logic signal inputs to each channel timer and its own lamp driver. Interchannel intervals were found to be an exact linear function of capacitance with I MF providing $5 \mathrm{msec}$ duration (see Fig. 1).

When using this method, it is important to remember that the auxilliary interchannel intervals must be subtracted from the setting of the inhibited channel timer in order to determine the actual stimulus duration for that channel. Thus, interstimulus intervals can be added to the existing programmable functions of the instrument when three stimuli are being presented.

\title{
Superphosphate in the control of vivarium odor
}

THOMAS B. COLLINS 1 and MARION D. HARLESS, ${ }^{2}$ CENTRAL WASHINGTON STATE COLLEGE, Ellensburg, Washington 98926

Odors are generally not a problem in the contemporary rodent vivarium, but they are often annoying in a restricted research situation. During long-term studies where minimal cage cleaning and interference is mandatory, ammonia effects may become objectionable as urine accumulates. White engaged in such research, the authors were able to minimize the irritating and odorous effects of ammonia buildup by using superphosphate. Superphosphate can either be mixed into the collecting tray material (sawdust, bagasse, commercial litters) or sprinkled over the surface of the material.

The commercially available liquids, wick devices, sprays, and gelatins are sometimes helpful in odor control. Although the cost of these agents is generally not prohibitively high, they are expensive. A greater deterrent to the use of the commercial agents is the odor they produce in an attempt to mask vivarium smells. Superphosphate, instead of introducing new odors to cover the ammonia odor, bonds with the free ammonia in the animals' urine, thus eliminating the ammonia as an irritant (Collings, 1949). According to county agricultural agents who were interviewed, phosphates and superphosphates have been used for some time as odor reducers by many poultrymen who maintain chickens on litter floors.

No actual data were collected, but superphosphate perceptibly diminished the irritating effects of ammonia buildup to the eyes and noses of human observers. It seems probable that the diminution was noticeable to the rodents involved; however, there were no observable changes in cage activity or ongoing behavioral testing following the introduction of the superphosphate.

Superphosphate currently costs less than $\$ 4.00$ for 80 pounds and may be purchased from any distributor of farm products. The amount to be used depends upon the moisture content of the collecting-tray litter, the number of animals per cage, etc., and is best determined through "trial and success."

\section{REFERENCE}

COLLINGS, G. G. Commercial fertilizers (4th ed.) Philadelphia: Blakiston, 1949.

\section{NOTES}

1. Now at Mankato State College, Mankato, Minnesots 56001.

2. Now at Midwestern University, Wichita Falls, Texas 76308. 